Diabetologia $9,145-151(1973)$

(C) by Springer-Verlag 1973

\title{
Role of Plasma Free Fatty Acids in the Control of Insulin Secretion in Man*
}

\author{
E. O. Balasse and H.A. Ooms \\ Metabolic Unit, St Pieter's Hospital and Laboratories of Experimental Medicine and of Clinical Chemistry, University \\ of Brussels, Belgium
}

Received: November 10, 1972, accepted: December 14, 1972

Summary. The aim of the present work was to study the effects of experimental changes in plasma free fatty acid (FFA) levels on basal insulin (IRI) concentration and on $\beta$ cell response to IV glucose, tolbutamide or glucagon in man. Each of the 53 subjects tested was studied on two separate occasions: i) in the basal state; ii) after an experimental decrease or increase in plasma FFA levels induced, respectively, by administration of nicotinic acid or the combination of a fat meal and heparin. The lowering of plasma FFA resulted in a small but significant fall in basal insulin concentration and in a $30 \%$ decrease in IRI response whatever the insulinotropic agent used. On the other hand, experimental elevation of plasma FFA enhanced pancreatic response to glucose $(+178 \%)$ and tolbutamide $(+58 \%)$, but did not alter significantly the IRI response to glucagon. Both the increase and the decrease in FFA concentration resulted in a reduction in the rate of glucose assimilation. - These results provide arguments for a role of plasma FFA in the control of insulin secretion and of insulin sensitivity in man.

Key words: Insulin secretion, insulin sensitivity, free fatty acids, nicotinic acid, fat meal, heparin, glucose, tolbutamide, glucagon.

\section{Introduction}

In addition to glucose, various other circulating substrates, such as aminoacids [1] and ketone bodies [2-4], are known to stimulate insulin (IRI) secretion in vivo. Free fatty acids (FFA) are also capable of stimulating insulin release in some species. This effect has been shown in vivo in dogs [5-8] and in vitro in rats [9]. In man, however, it has been observed that experimental elevations of plasma FFA concentration do not significantly increase basal IRI levels [10-11]. This does not necessarily indicate that human $\beta$ cells are insensitive to changes in concentration of this substrate. Indeed, Schalch and Kipnis [10] and Balasse and Ooms [11] have shown that the insulin response to giucose is enhanced when FFA concentrations are elevated as the result of the combined administration of a fat meal and heparin.

Owing to the obvious physiological importance of such a phenomenon, we have attempted in the present work to extend these earlier findings. Therefore we have tested whether experimental elevations or reductions in plasma FFA levels in man can modify the IRI response to various insulinotropic agents, namely glucose, tolbutamide and glucagon.

\section{Material and Methods}

The studies were performed on $\mathbf{5 3}$ ambulatory subjects of both sexes, aged $15-60$ years (mean 33 years), after an overnight fast.

* Work partially carried out under contract of the Fonds de la Recherche Scientifique Médicale ( ${ }^{\circ}$ 20193) and under contract of the Ministère de la Politique Scientifique within the framework of the Association EuratomUniversity of Brussels - University of Pisa.
In a first group of 26 obese subjects (body weight averaging $144 \%(122-183)$ of ideal weight), we studied the effect of an experimental decrease in FFA concentration on IRI response to 3 different insulinotropic substances i.e. glucose (25 g; 13 subjects), tolbutamide (1 g; 6 subjects) or glucagon $(0.25 \mathrm{mg} ; 7$ subjects $)$, all agents being injected IV in 1 min. Each subject was submitted to a given test of pancreatic stimulation on 2 separate days: on one day, the test was performed in the basal state (control test); on the other day, repeated IV injections of an antilipolytic agent (nicotinic acid, $100 \mathrm{mg}$ every $15 \mathrm{~min}$ ) were started $2 \mathrm{~h}$ before the test and continued until the end of the experiment.

In a second group of 27 subjects (body weight averaging $114 \%(82-148)$ of ideal weight) we tested the effect of an elevation of plasma FFA levels on $\beta$ cell secretion. The IRI response to IV glucose (12 subjects), tolbutamide ( 7 subjects) or glucagon ( 8 subjects) was measured both in the basal state and after administration of a fat meal and heparin. In this case, $250 \mathrm{ml}$ of milk cream (containing $100 \mathrm{~g}$ of triglycerides) was given orally $4 \mathrm{~h}$ before the test and followed by the IV injection of heparin $2 \mathrm{~h}(40 \mathrm{mg})$, $1 \mathrm{~h}\left(20 \mathrm{mg}^{\circ}\right)$ and immediately before $(20 \mathrm{mg})$ the injection of the insulinotropic agent.

During the various tests, plasma concentrations of glucose, FFA and IRI were determined on venous blood samples obtained at intervals as shown in Figs. 1-3.

The time interval between 2 tests performed in the same individual varied between 1 and 7 days (mean 3 days) and subjects were instructed not to change their usual diet during this period. In 43 subjects, the control tost was performed first whereas it was performed second in the 10 remaining subjects distributed in both groups. The order of sequence of the tests was without apparent infuence on the results.

Plasma glucose was determined by the method of Hoffmann [12] adapted to the Technicon Autoanalyser. In the subjocts submitted to an IV glucose test, " $\mathrm{K}$ " value was determined according to Conard [13]. Plasma FFA were estimated according to Trout et al. [14]. In studies where FFA were elevated with a fat meal and heparin, in vitro lipolysis after sampling was prevented as described elsewhere (11). Plasma IRI was assayed according to Morgan and Lazarow [15], using human insulin as standards. The addition of nicotinic acid to 
normal plasma $(10-50 \mu \mathrm{g} / \mathrm{ml})$ did not affect IRI determination. The concentration of circulating nicotinic acid to be expected in our studies should be around $10 \mu \mathrm{g} / \mathrm{ml}$ [35].

\section{Results}

I. Effects of changes in FFA levels on basal glucose and IRI concentrations

Mean changes in FFA, glucose and IRI concentration resulting from repeated injections of nicotinic acid to 27 subjects are presented in Fig. 1. Starting

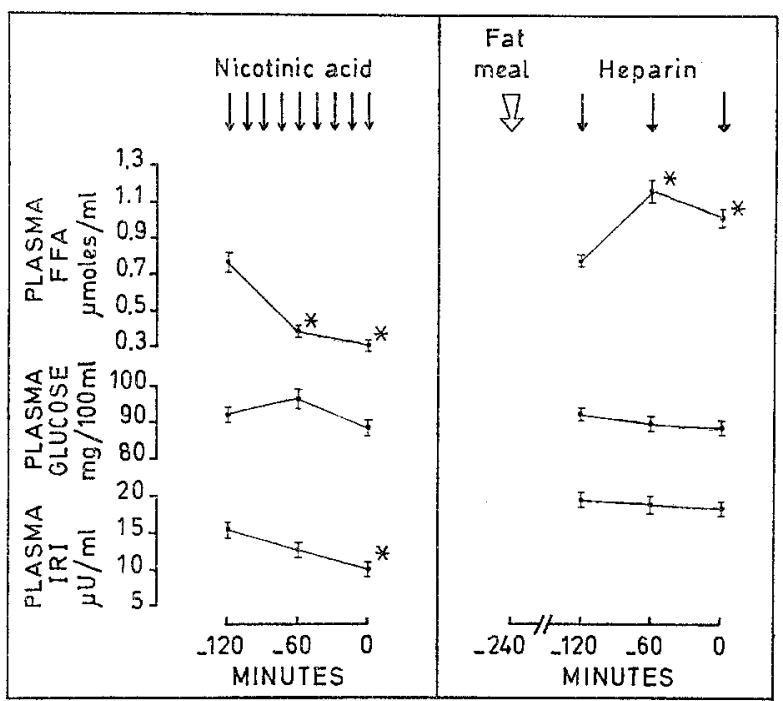

Fig. 1. Plasma concentrations of FFA, glucose and IRI after administration of nicotinic acid (27 subjects) or of a fat meal and heparin ( 20 subjects). (Mean $t$ SEM).

* values being significantly different $(p<0.001)$ from initial concentration

from an average initial value of $0.78 \mu$ moles $/ \mathrm{ml}, \mathrm{FFA}$ concentration attained 0.40 umoles $/ \mathrm{ml}$ after $60 \mathrm{~min}$ and $0.32 \mu$ moles $/ \mathrm{ml}$ after $120 \mathrm{~min}$ of nicotinic acid treatment, this fall being highly significant. Glycaemia remained unchanged whereas IRI levels decreased significantly, averaging $15.5 \mathrm{\mu U} / \mathrm{ml}$ in the basal state and $10 \mu \mathrm{U} / \mathrm{ml} 120$ min after starting the injections of nicotinic acid.

On the other hand, the administration of heparin, to 20 subjects given a fat meal $2 \mathrm{~h}$ earlier significantly increased FFA concentration, which averaged, respectively, 0.80 umoles $/ \mathrm{ml}, 1.18$ umoles $/ \mathrm{ml}$ and 1.03 umoles/ml before, $60 \mathrm{~min}$ after and $120 \mathrm{~min}$ after starting heparin treatment. This rise had no effect on glycaemia nor on IRI concentration.

II. Effects of changes in FFA concentration on IRI response to glucose, tolbutamide or glucagon

Figs. 2 and 3 represent the average concentrations of glucose, IRI and FFA measured during the 3 different tests of pancreatic stimulation performed in the control state and after administration of nicotinic acid or of a fat meal plus heparin. Tables 1 and 2 provide individual values which were obtained in the following way: the various concentrations of FFA and IRI observed during a test performed after nicotinic acid or after a fat meal plus heparin were expressed as percent of corresponding values obtained in the same test performed in the same subject under control conditions; they were then averaged. Experimental values taken into account in calculating these means were those obtained from - $90 \mathrm{~min}$ onwards for FFA (time of the first sample after nicotinic acid or heparin) and from +2 min onwards for IRI (time of the first sample

Table 1. Iffect of the administration of nicotinic acid on FF $A$ concentration, glucose " $K$ " value and IRI response to IV glucose, IV tolbutamide or IV glucagon

\begin{tabular}{|c|c|c|c|c|c|c|c|}
\hline & IV gl & lucose & & $\begin{array}{l}\text { IV t } \\
\text { amid }\end{array}$ & olbut- & $\begin{array}{l}\text { IV } \\
\text { cag }\end{array}$ & n \\
\hline & FFA & $\mathrm{K}$ & IRI & FFA & IRI & & \\
\hline & $\%$ of & f cont & ol valu & & & & \\
\hline & 80 & 70 & 58 & 28 & 77 & 32 & 39 \\
\hline & 81 & 108 & 48 & 76 & 42 & 74 & 74 \\
\hline & 60 & 48 & 54 & 64 & 61. & 46 & 49 \\
\hline & 50 & 50 & 27 & 25 & 59 & 91 & 108 \\
\hline & 39 & 81 & 94 & 62 & 105 & - & 75 \\
\hline & 78 & 41 & 132 & - & 74 & 92 & 49 \\
\hline & 49 & 53 & 67 & & & 66 & 73 \\
\hline & 43 & 37 & 63 & & & & \\
\hline & 55 & 55 & 58 & & & & \\
\hline & 52 & 77 & 85 & & & & \\
\hline & 95 & 100 & 80 & & & & \\
\hline & 70 & 71 & 59 & & & & \\
\hline & 61 & 117 & 69 & & & & \\
\hline Mean & 63 & 70 & 68 & 51 & 69 & 64 & 66 \\
\hline SEM & 5 & 7 & 8 & 10 & 9 & 11 & 10 \\
\hline $\mathrm{P}$ & $<.001$ & $<.01$ & $<.01$ & $<.01$ & $<.02$ & $<.02$ & $<.02$ \\
\hline
\end{tabular}

Results are expressed as percent of corresponding values obtained during a control test in the same subject (for details in methods of calculation, see section "Results").

after injection of the insulinotropic agent). " $K$ " values obtained from the IV glucose tests are also presented in Tables 1 and 2 and expressed as percent of control values.

a) Effect of nicotinic acid on insulin secretion (Fig. 2 and Table 1). The administration of nicotinic acid resulted in a decrease in FFA concentration which was already apparent after $30 \mathrm{~min}$ and which persisted until the end of the tests (Fig. 2). Average FFA levels in studies with nicotinic acid amounted to $51-64 \%$ of values observed in the control studies (Table 1 ). This fall in FFA concentration was accompanied by a blunted pancreatic response to secretory agents. After nicotinic acid, IRI response to glucose, tolbutamide or glucagon, represented respectively $68 \pm 8 \%$ (SEM), $69 \pm 9 \%$ and $66 \pm 10 \%$ of control responses (Table 1 ) whereas glycaemic curves were minimally influenced (Fig. 2). In studies with IV glucose, the " $\mathrm{K}$ " value averaged $1.67 \%$ per min in the control experiments and was reduced by $30 \%(p<0.01)$ after nicotinic acid (Table 1). 
Table 1 shows that there are important individual variations in the effects of nicotinic acid on IRI response to the stimulatory agents. Furthermore, there is no correlation between the fall in FFA concentration and the inhibition of pancreatic response nor is there a correlation between the latter and the deterioration of the " $K$ " value.

b) Effect of the administration of a fat meal and heparin on insulin secretion (Fig. 3 and Table 2). The administration of a fat meal did not significantly altered by the elevated FFA levels. For the IV glucose test, the " $K$ " value averaged $1.63 \pm 0.2 \%$ (SEM) per min in the basal state and decreased by $11 \%$ after the fat meal and heparin, this fall being not statistically significant ('Table 2).

When all individual results of this study are considered, a positive correlation is found $(r=0.59$; $p<0.001$ ) between changes in FFA concentrations (whether increased or decreased) and corresponding modifications in IRI response (Fig. 4), whatever the insulinotropic agent used.

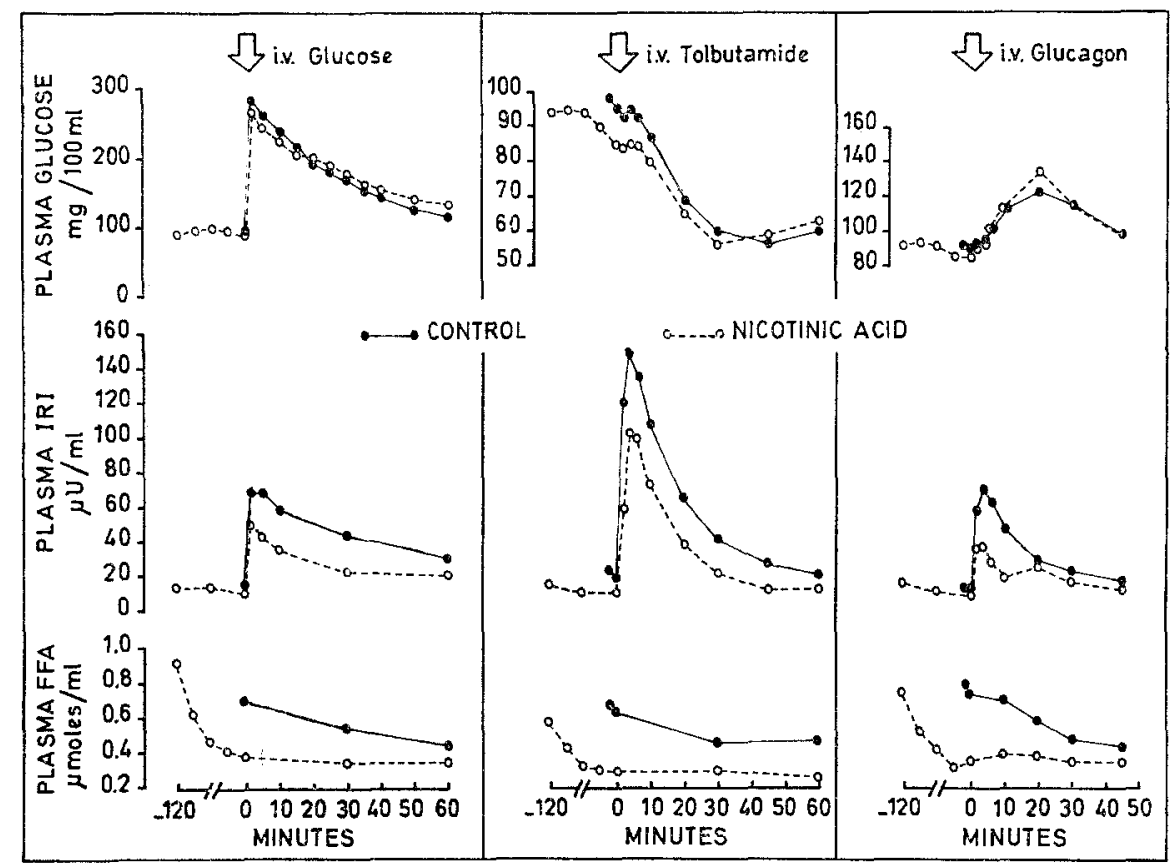

Fig. 2. Average concentration of plasma glucose, IRI and FFA after IV glucose (13 subjects), IV tolbutamide (6 subjects) or IV glucagon (7 subjects) in the basal state (•-) and during administration of nicotinic acid (o--.--o)

change the plasma FFA concentration. After heparin, there was a sharp rise in FFA levels which peaked at about $1.2 \mu$ moles $/ \mathrm{ml} 30$ to $60 \mathrm{~min}$ after the first heparin injection. Subsequently, despite an additional injection of this drug, there was a slow decrease in FFA levels, further accentuated by the administration of the insulinotropic agents. On an average, FFA levels observed during the studies performed after the fat meal and heparin amounted to $140-192 \%$ of values obtained under control conditions (Table 2). These elevated levels of FFA were accompanied by a significantly increased insulin response to glucose and tolbutamide, representing respectively $278 \pm 79 \%$ (SEM) and $158 \pm 17 \%$ of control response. However, there is no correlation between elevations of FFA and degree of enhancement of insulin secretion. The insulin response to glucagon was not significantly enhanced after the fat meal and heparin, despite a major increase in FFA levels. Glycaemic curves after IV glucose, tolbutamide or glucagon were minimally

\section{Discussion}

\section{Effects of changes in FFA levels on basal concen-} tration of glucose and IRI.

The absence of significant modification of basal glucose and IRI concentrations after a fat meal and heparin has been documented in other studies $[10,11]$. In our experiments, the lowering of FFA levels by nicotinic acid was also without effect on glycaemia, but resulted in a small, progressive decrease in IRI concentration which was statistically significant $2 \mathrm{~h}$ after the onset of the nicotinic acid injections. Since this drug seems to be devoid of any direct inhibitory effect on $\beta$ cell secretion $[16,17]$, it is possible that the observed fall in IRI concentration might be related to the reduction in FFA levels.

Opposite results were described by Miettinen $e t$ al. [18] who observed an increase in basal IRI concentration after nicotinic acid, but their observations were 
limited to the initial 30 min after nicotinic acid infusion and thus cannot be compared with ours.

\section{Effects of changes in FFA concentrations on IRI} response to glucose, tolbutamide and glucagon

Our results indicate that an increase in FFA levels following administration of a fat mealand heparin results in an enhancement of IRI response to glucose, tolbutamide or glucagon, whereas the decrease in FFA level observed after nicotinic acid inhibits the insulin response to these agents. It should be mentioned, however, that the increase in pancreatic response to glucagon after a fat meal and heparin was not statistically significant. This might be due to the small number of patients tested. Among the 53 patients included in the whole study, only 7 had an "unexpected" response and there is a highly significant positive correlation between variations in FFA levels and

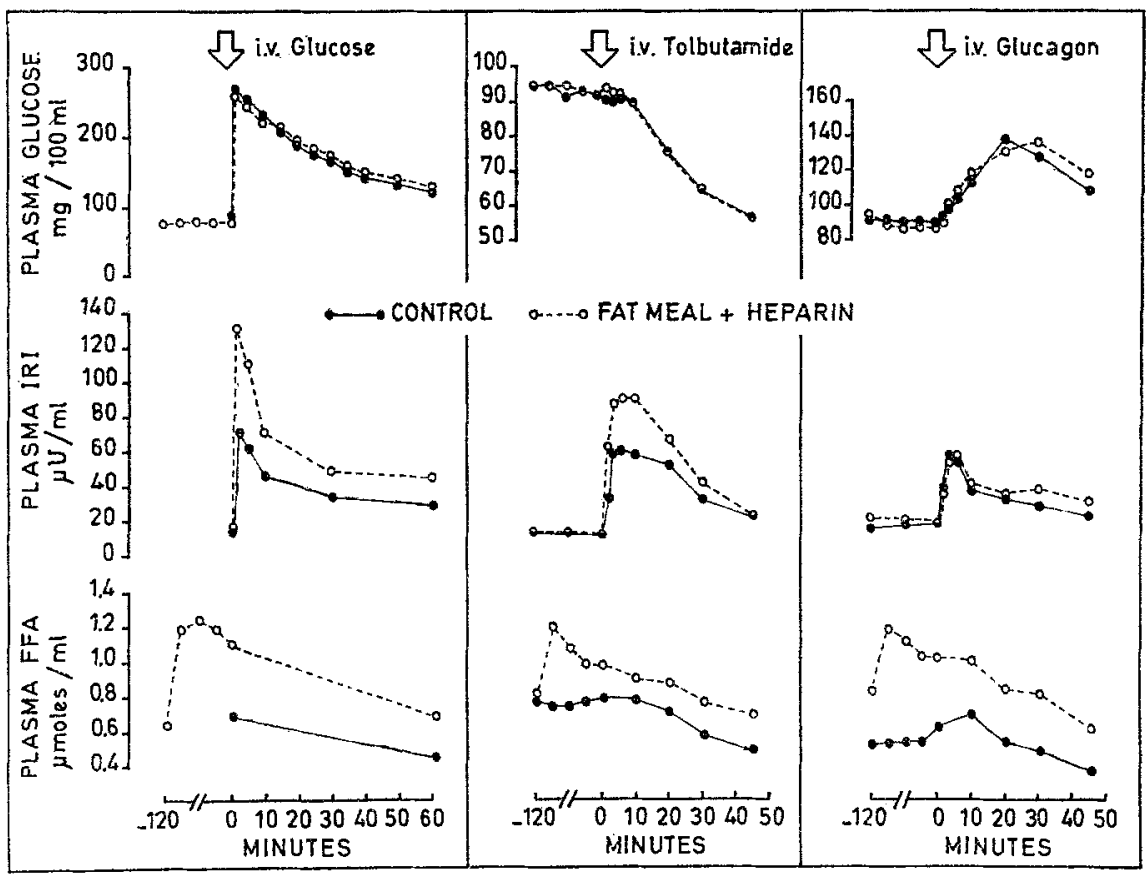

Fig. 3. Average concentration of plasma glucose, IRI and FFA after IV glucose (12 subjects), IV tolbutamide (7 subjects) or IV glucagon (8 subjects) in the basal state (-—) and after administration of a fat meal and heparin (0---.-o)

Table 2. Iffect of the administration of a fat meal and heparin on $F F A$ concentration, glucose " $K$ " value and $I R I$ response to IV glucose, IV tolbutamide or IV glucagon

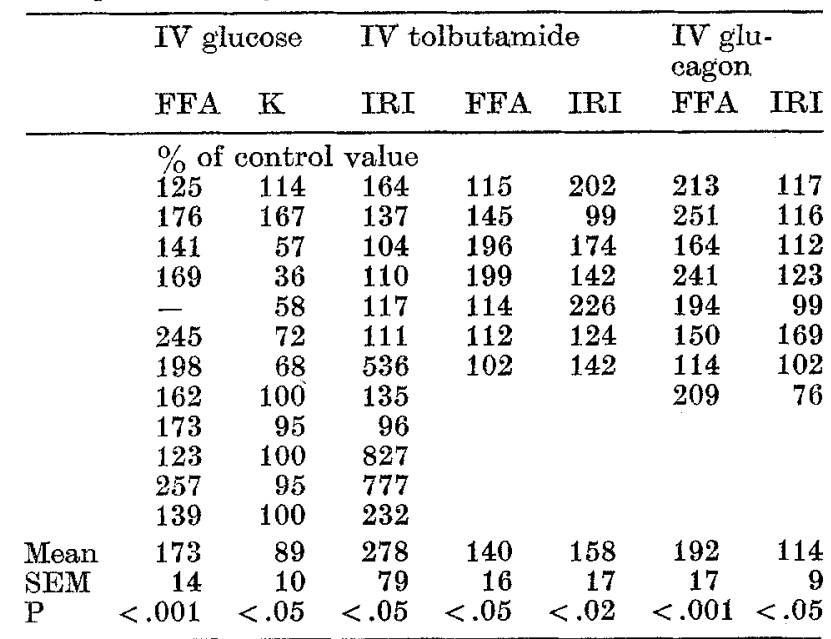

Results are expressed as percent of corresponding values obtained during a control test in the same subject (for details in methods of calculation, see section "Results"). changes in IRI response. However, as this is not the case in individual subgroups, the causative relationship between changes in FFA and corresponding changes in IRI might be questioned. The fact that the fat meal - heparin regimen on one hand and nicotinic acid on the other hand might influence pancreatic reactivity independently of the changes in FFA concentration they induce, should be taken into consideration. Indeed, the fat meal per se, which does not increase FFA levels, could enhance islet cell response, for instance through secretion of gastro-intestinal hormones. The observations of Schalch and Kipnis [10] in man and of Szabo and Mahler [19] in dogs do not substantiate this possibility. Pelkonen et al. [20] have noticed an increase in IRI response to IV glucose after a fat meal alone but the difference was statistically significant only at the 5 th min of the test. A direct inhibitory effect of nicotinic acid on insulin secretion also seems improbable, according to in vitro data already mentioned $[16,17]$. It is therefore reasonable to assume that the effects of the fat meal - heparin regimen or of nicotinic acid are due to concomitant changes in FFA concentration. The absence of correla- 
tion between FFA changes and IRI response in the individual subgroups might be explained if intracellular ( $\beta$ cell) rather than plasma FFA concentrations were the critical factor in regulating insulin release. Indeed, it has been shown by Schonfeld and Kipnis that, at least in rat muscle, these two concentrations are not rapidly equilibrated $[21,22]$.

Several other reports have demonstrated that experimental increases in plasma FFA concentration

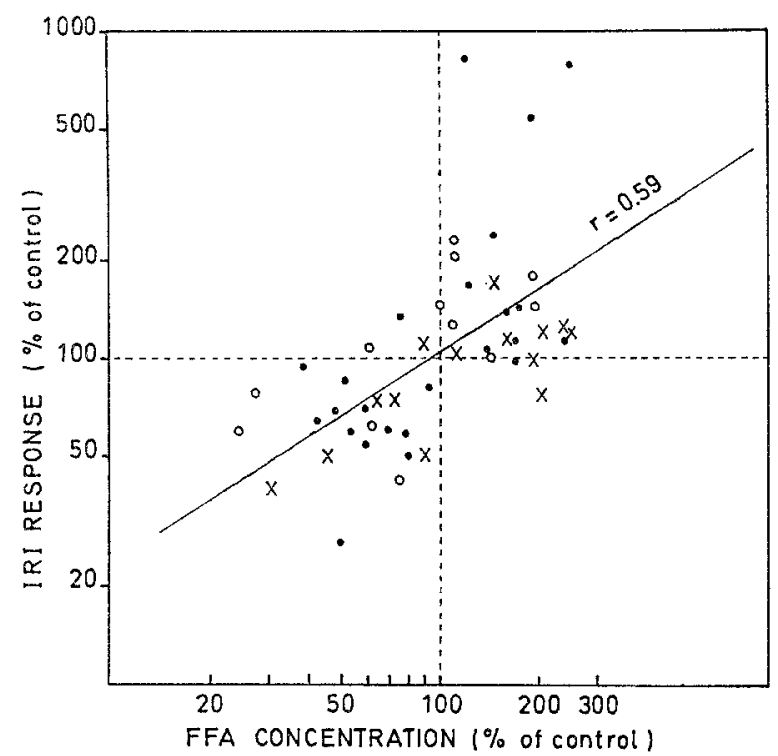

Fig. 4. Correlation between IRI response to IV glucose $(\bullet)$, tolbutamide (o) or glucagon (x) and FFA concentration. The tests were performed either after a fat meal plus heparin or during administration of nicotinic acid and individual results are expressed as \% of values observed during a control test in the same subject. Bilogarithmic coordinates

obtained by a fat meal and heparin [10-11], by IV infusion of a fat emulsion [23, 24], or by intraduodenal infusion of octanoic acid [25] enhance the insulin response to glucose. Our data confirm these observations and indicate that this potentiating effect of FFA on insulin release also applies when tolbutamide and possibly glucagon are used as stimulatory agents.

The effects of nicotinic acid on IRI response to glucose have been studied by several authors with conflicting results: Miettinen et al. [18] observed no change in IRI response to IV glucose given $30 \mathrm{~min}$ after $200 \mathrm{mg}$ of nicotinic acid, while Stowers et al. [26], Büber et al. [27] and Gómez et al. [24] noticed a blunted pancreatic response to oral glucose given $2 \mathrm{~h}$ after the start of an infusion of nicotinic acid or of a related compound. Since in our studies, the inhibitory effect was also observed after $2 \mathrm{~h}$ of nicotinic acid treatment, it seems probable that the negative results published by Miettinen et $a l$. should be ascribed to the fact that exposure to nicotinic acid was of much shorter duration. Our experiments also indicate that reduced FFA levels inhibit pancreatic response not only to glucose but also to other insulinotropic agents such as tolbutamide and glucagon. Since the insulinotropic effect of these two substances is known to be modulated by the availability and further metabolism of glucose in the $\beta$ cell $[28,17]$, it is reasonable to hypothesize, in agreement with Montague et al. [29], that FFA may influence the secretory process by inhibiting glycolysis in islet tissue in much the same way as they do in muscle.

\section{Effects of changes in FFA concentration on} glucose " $K$ " value

On average, the glucose " $\mathrm{K}$ " value decreased after the fat meal plus heparin, but individual responses were variable and the changes observed are not statistically significant. As pointed out in a previous work from this laboratory [11], the greater the control " $K$ " value, the greater the fall observed after a fat meal and heparin. This trend was confirmed in the present series: the average " $K$ " value was $1.63 \%$ per min for the whole group, $1.12(0.9-1.5) \%$ per min for the patients who did not respond to the rise in FFA levels by a fall in " $\mathrm{K}$ " value, and $2.0(1.2-2.8) \%$ per $\min$ in those who did respond.

Several workers, using various experimental protocols, also came to the conclusion that elevated FFA levels tend to decrease glucose assimilation. Schalch and Kipnis observed a fall in " $K$ " value in 10 out of 12 subjects given a fat meal and heparin and the percent fall was positively correlated to the percent increase in FFA concentration [10]. We did not observe such a correlation. A deterioration of oral glucose tolerance was observed by Gómez et al. [24] during the infusion of a triglyceride emulsion in man, while Balasse has shown that the administration of a fat emulsion and heparin reduces the rate of uptake and of oxidation of infused glucose in insulinized dogs [30]. In contrast, Pelkonen et al. [20] observed no significant effect of a fat meal and heparin on " $K$ " value in man, but their study was limited to 5 cases only.

The fact that, in the present experiments, the enhancement in IRI release after the glucose load was not accompanied by an increase in its removal rate constant suggests that increased FFA concentration induced insulin resistance. This confirms our earlier results obtained with exogenous insulin [11].

Nicotinic acid produced a significant decrease in " $\mathrm{K}$ " value averaging $30 \%$, thus confirming the results published by Miettinen et al. [18]. These data are not in accord with the "glucose fatty acid cycle" theory [31], according to which a fall in FFA availability should result in a stimulation of glucose utilization at least by muscle. Other studies, using ${ }^{14} \mathrm{C}$-glucose in vivo have shown that nicotinic acid increases the rate of glucose uptake and oxidation in dogs [32] and in rats [33]. Recent work from our laboratory indicates that this is also the case in starved and overnight-fasted humans, despite the fact that nicotinic acid produces a 
slight decrease in basal insulin concentration [34]. The possible causes of the discrepancy between the effect of nicotinic acid on glucose utilization, whether it is measured by use of a glucose load or by use of tracer glucose, have been discussed by Miettinen et al. [18]. These authors have suggested that the decreased " $\mathrm{K}$ ", value might be caused by an impairment in the assimilation of glucose by the liver through some action of nicotonic acid not related to antilipolysis. Although this explanation cannot be ruled out, our data suggest another possibility. Indeed, the reduction in " $\mathrm{K}$ " value after nicotinic acid could be accounted for by the inhibition of IRI response to glucose which masks the stimulatory effect of reduced FFA levels on glucose utilization. On the other hand, when the rate of glucose utilization is measured under normoglycaemic conditions with use of a tracer, nicotinic acid induces only a minor fall in basal IRI levels which does not interfere with the operation of the "glucose fatty acid cycle".

In conclusion, the main purpose of this work was to provide arguments suggesting that FFA levels exert a regulatory effect on IRI secretion in man in response to a variety of stimuli. It should be kept in mind, however, that these arguments are based on studies in which changes in FFA levels have been induced by unphysiological means. The possible relationship between FFA and pancreatic response might well have important pathophysiological implications. In many situations where hyperinsulinism is found, as in obesity or acromegaly, there is also an exaggerated high level of plasma FFA. Our data suggest that the latter might be one causative factor of the hyperinsulinism. As high levels of FFA are also capable of inducing insulin resistance, this substrate might be involved in the development of the hormonal syndrome associating hyperinsulinism and insulin resistance [35], which is believed to be of primary importance in the genesis of various diabetic states.

Acknowledgements. The authors wish to thank Mrs D. Calay, M. A. Neef and A. Vanderborght and Mr G. Delvigne for skillfull assistance.

\section{References}

1. Floyd, J.C., Jr., Fajans, S.S., Conn, J.W., Knopf, R.F., Rull, J.: Stimulation of insulin secretion by aminoacids. J. clin. Invest. 45, 1487-1502 (1966).

2. Madison, L.L., Mebane, D., Unger, R.H., Lochner, A.: The hypoglycemic action of ketones. II. Evidence for a stimulatory feedback of ketones on the pancreatic beta cell. J. clin. Invest. 43, 408-415 (1964).

3. Balasse, E., Couturier, E., Franckson, J.R.M.: Influence of sodium- $\beta$-hydroxybutyrate on glucose and free fatty acid metabolism in normal dogs. Diabetologia 3, 488-493 (1967).

4. Balasse, E.O., Ooms, H.A., Lambilliotte, J.P.: Evidence for a stimulatory effect of ketone bodies on insulin secretion in man. Horm. Metab. Res. 2, 371 $372(1970)$.
5. Greenough, W.B. III, Crespin, S.R., Steinberg, D.: Hypoglycemia and hyperinsulinemia in response to raised free fatty acid levels. Lancet 1967 II, 13341337.

6. Crespin, S.R., Greenough, W.B. III, Steinberg, D.: Stimulation of insulin secretion by infusion of free fatty acids. J. clin. Invest. 48, 1934-1943 (1969).

7. Seyffert, W.A. Jr., Madison, L.L.: Physiologic effects of metabolic fuels on carbohydrate metabolism. I. Acute effect of elevation of plasma free fatty acids on hepatic glucose output, peripheral glucose utilization, serum insulin and plasma glucagon levels. Diabetes 16, 765-776 (1967).

8. Balasse, E.O.: Régulation du métabolisme extrahépatique des corps cétoniques in vivo, p. 62 . Bruxelles: Presses Universitaires 1971.

9. Malaisse, W.J., Malaisse-Lagae, F.: Stimulation of insulin secretion by non-carbohydrate metabolites. J. Lab. clin. Med. 72, 438-448 (1968).

10. Schalch, D.S., Kipnis, D. M.: Abnormalities in carbohydrato tolerance associated with elevated plasma nonesterified fatty acids. J. clin. Invest. 44, 20102020 (1965).

11. Balasse, F., Ooms, H.A.: Effet d'une élévation aiguë du taux des acides gras libres (NEFA) sur la tolérance glucidique et la réponse insulinique à l'hyperglycémie chez l'homme normal. Rev. franç. Et. Clin. Biol. 13, $62-67(1968)$

12. Hoffmann, W.S.: A rapid photoelectric method for the determination of glucose in blood and urine. J. biol. Chem. 120, 51-55 (1937).

13. Conard, V.: Mesure de l'assimilation du glucose. Bases théoriques et applications cliniques. Bruxelles: Acta Medica Belgica 1955.

14. Trout, D.L., Estes, E.H., Friedberg, S.J.: Titration of free fatty acids of plasma: a study of current methods and a new modification. J. Lipid Res. 1, $199-212(1960)$.

15. Morgan, C.R., Lazarow, A.: Immuno-assay of insulin: two antibody system. Diabetes 12, 115-126 (1963).

16. Michaelis, D., Hahn, H.J., Michael, R., Knospe, S., Schäffer, H., Jutzi, E., Wulfert, P.: Effekte der intravenösen nikotinsäureinfusion auf substrat-, metabolit-, und hormonkonzentrationen im blut beim juvenil-manifestierten diabetes mellitus. Diabetologia 6, $550-557(1970)$

17. Malaisse, W., Malaisse-Lagae, F., Mayhew, D.: A possible role for the adenylcyclase system in insulin secretion. J. clin. Invest. 46, 1724-1734 (1967).

18. Miettinen, T.A., Taskinen, M., Pelkonen, R., Nikkilä, E.A.: Glucose tolerance and plasma insulin in man during acute and chronic administration of nicotinic acid. Acta Med. Scand, 186, 247-253 (1969).

19. Szabo, O., Mahler, R.J.: The influence of fatty acid ingestion upon oral glucose tolerance. Horm. Metab. Res. 3, 299-300 (1971).

20. Pelkonen, R., Miettinen, T. A., Taskinen, M., Nikkilä, E.A.: Effect of acute elevation of plasma glycerol, triglyceride and FFA levels on glucose utilization and plasma insulin. Diabetes 17, 76-82 (1968).

21. Schonfeld, G., Kipnis, D.M.: Effects of fatty acids on carbohydrate and fatty acid metabolism of rat diaphragm. Amer. J. Physiol. 215, 513-522 (1968).

22. Schonfeld, G., Kipnis, D.M.: Glucose-fatty acid interactions in the rat diaphragm in vivo. Diabetes 17, $422-426$ (1968).

23. Felber, J.P., Vannotti, A.: Effects of fat infusion on glucose tolerance and plasma insulin levels. Med. Exp. 10, $153-156$ (1964).

24. Gómez, F., Jéquier, E., Chabot, V., Büber, V., Felber, J.P.: Carbohydrate and lipid oxidation in normal human subjects: its influence on glucose tolerance and insulin response to glucose. Metabolism 21, 381-391 (1972). 
25. Linscheer, W.G., Slone, D., Chalmers, T.C.: Effects of octanoic acid on serum levels of free fatty acids, insulin and glucose in patients with cirrhosis and in healthy volunteers. Lancet 1967 I, 593-597.

26. Stowers, J.M., Bewsher, P. D., Stein, J.M., Mowat, J. : Effect of nicotinic acid or derivatives on plasma insulin in man. In: Metabolic effects of nicotinic acid and its derivatives, p. 913-921, R. G. Goy and L.A. Carlson, Eds. Bern: Hans Huber Publishers 1971.

27. Büber, V., Felber, J.P., Vannotti, A.: Verbesserung der oralen glukosetoleranz durch akute medikamentöse verminderung der freien fettsäuren im plasma. Schweiz. med. Wschr. 98, 711-713 (1968).

28. Cerasi, E., Chowers, I., Luft, R., Widström, A.: The significance of the blood glucose level for plasma insulin response to intravenously administered tolbutamide in healthy subjects. Diabetologia $5,343-348$ (1969).

29. Montague, W., Taylor, K.W.: Regulation of insulin secretion by short chain fatty acids. Nature 217, 853 (1968).

30. Balasse, E. O.: Effect of free fatty acids and ketone bodies on glucose uptake and oxidation in the dog. Horm. Metab. Res. 3, $403-409$ (1971).
31. Randle, P.J., Garland, P. B., Hales, C.N., Newsholme, E.A.: The glucose fatty-acid cycle. Its role in insulin sensitivity and the metabolic disturbances of diabetes mellitus. Lancet 1963 I, 785-789.

32. Paul, P., Issekutz, B. Jr., Miller, H.I.: Interrelationship of free fatty acids and glucose metabolism in dogs. Amer. J. Physiol. 211, 1313-1320 (1966).

33. Root, M. A., Ashmore, J.: The hypoglycemic activity of nicotinic acid in rats. Naunyn-Schmiedeberg Arch. Pharm. Exp. Path. 248, 117-123 (1964).

34. Balasse, E.O., Neef, M. A. : Influence of nicotinic acid on the rates of turnover and oxidation of plasma glucose in man (to be published).

35. Svedmyr, N., Harthon, L., Lundholm, L.: The relationship between the plasma concentration of free nicotinic acid and some of its pharmacologic effects in man. Clin. Pharmacol. Therap. 10, 559-570 (1969).

Dr. E. O. Balasse

Laboratory of Experimental Medicine

University of Brussels

115 , Blvd. de Waterloo

Brussels

Belgium 